\title{
FILAMENTOUS GROWTH IN SACCHAROMYCES CEREVISIAE
}

\author{
Sandra Regina Ceccato-Antonini1 ${ }^{*}$; Peter Edwin Sudbery ${ }^{2}$ \\ ${ }^{1}$ Departamento de Tecnologia Agroindustrial e Socio-Economia Rural, Universidade Federal de São Carlos, Araras, SP, Brasil, \\ ${ }^{2}$ Molecular Biology and Biotechnology Department, Firth Court, University of Sheffield, UK
}

Submitted: December 12, 2003; Returned to authors for corrections: April 26, 2004; Approved: August 02, 2004

\section{MINI-REVIEW}

\begin{abstract}
Fungal dimorphism is a complex phenomenon triggered by a large variety of environmental factors and consists of a reversible alternating pattern of growth between different elliptical and filamentous forms of cells. Understanding the mechanisms that regulate these events is of major interest because of their implications in fungal pathogenesis, cell differentiation and industry. Diploid cells of Saccharomyces cerevisiae transform from budding yeast to pseudohyphae when starved for nitrogen, giving the cells an advantage in food foraging, which is sensed by at least two signal transduction pathways: the MAP kinase (MAPK) and the PKA (cAMP-dependent protein kinase A) pathways. The output of these signalling pathways is the expression of pseudohypha-specific genes, whose expression profiles change and is accompanied by a G2 delay in the cell cycle and a prolonged period of polarized growth. Haploid yeast strains show a similar growth type after prolonged incubation on rich medium plates. The cells form chains and invade the agar on the edge of the colony, but they do not become elongated. This growth type is referred to as haploid invasive growth. Alcohols can also induce filamentous growth in S. cerevisiae, promoting aberrant and elongated morphology. The three forms of filamentous growth are revised in this article and also the pathways involved in sensing, signaling and signal transduction during filamentous growth.
\end{abstract}

Key words: filamentation, Saccharomyces cerevisiae, pseudohyphae

\section{INTRODUCTION}

Simple fungi have evolved sophisticated mechanisms to sense and respond to environmental cues by activating developmental switches that result in coordinated changes in cell physiology, morphology and cell adherence. Critical depletion of nutrients often induces growth arrest to form spores capable of tolerating a wide range of environmental stresses. However, an alternative response is the dimorphic switch to filamentous growth, characterized by branching networks of chains of cells or hyphae to form a mycelium $(14,44)$.

Filamentous growth is considered an important adaptive response that functions analogously to cell motility in allowing a starving fungal colony to forage for nutrients (27). Branching filaments permit wider exploration of the environment at a lower biomass (energy) cost than non-filamentous growth. Cell-cell adherence and highly polarized growth promote invasion of the substrate (14). Further, the high surface-to-volume ratio of filaments may facilitate transport of nutrients.

The dimorphic switch is essentially modular and may be activated by a wide range of stimuli appropriate to the lifestyle of the fungus. Typically, the dimorphic switch in pathogenic fungi is tuned such that cells elongate or increase cell-cell adherence when exposed to their host (53). Such regulated dimorphism has been established as an important virulence factor, determining invasion and colonization by pathogenic organisms such as Candida albicans, Magnaporthe grisea (rice blast) and Ustilago maydis (corn smut) $(28,53)$. Thus the

\footnotetext{
* Corresponding author. Mailing address: Caixa Postal 153, CEP 13600-970, Araras, SP, Brasil. Tel.: (+5519) 3543-2614. E-mail: antonini@cca.ufscar.br
} 
dimorphic switch may prove to be an attractive target for chemical intervention in the prophylaxis and treatment of fungal infections in medicine and agriculture.

In turn, many industrial biochemical processes employ dimorphic yeasts and filamentous fungi to drive production of desired chemical compounds. Fermentation of carbohydrates in fruits, grains and other biomass to ethanol by Saccharomyces cerevisiae is the critical process for a wide range of products from fine wines to gasoline additives $(44,49)$.

The well known baker's or brewer's yeast, S. cerevisiae, grows usually as single budding cells. Although scattered observations on the ability of this yeast to grow in a filamentous form were made long ago (Guilliermond, 1920 apud Gancedo (14)), the fact that most laboratory strains grow exclusively in the unicellular form (23) meant that dimorphism in this yeast did not receive significant attention until the last decade. In 1992, Gimeno et al. (17) reported that, in a particular diploid strain of S. cerevisiae, nitrogen starvation caused formation of pseudohyphae and led to filamentous growth. During pseudohyphal growth, the cells become elongated, budding occurs synchronously in unipolar fashion and the buds do not separate, producing the chains of cells which are called pseudohyphae.

Some $S$. cerevisiae haploid strains may also show a change in morphology, for instance, after extended growth on YPD plates (50). This has been called invasive growth because the filaments penetrate within the agar, below the colony. Such growth is characterized by a slight elongation of cells, along with a switch from an axial to a bipolar budding pattern.

Several alcohols can also induce morphological abnormalities. Dickinson $(9,10)$ showed that some fusel alcohols, which remain after most of the ethanol has been removed from any yeast fermentation, can promote an aberrant, elongated morphology in S. cerevisiae. The morphology of cells growing in the pseudohyphal form is very similar to that of cells exposed to these fusel alcohols. Lorenz et al. (34) characterized the connection between these alcohol-induced morphological changes and pseudohyphal growth. Several alcohols, notably isoamyl alcohol and butanol, promote a filamentous growth on solid medium and an elongated and filamentous form in liquid medium. Ethanol also enhanced filamentous growth in diploid cells.

The three forms of filamentous growth are revised in the following items and also the pathways involved in sensing, signaling and signal transduction during filamentous growth.

\section{NITROGEN STARVATION}

Laboratory culture conditions for S. cerevisiae, whether in liquid media or on solid agar, have been developed to optimize cell growth. Typically, these conditions initially provide an excess of all necessary nutrients. Cells respond to such rich media containing abundant nitrogen sources and a fermentable carbon source by adopting a dispersed yeast form and growing rapidly, with the fermentation mixed actively by evolved carbon dioxide and/or mechanical agitation. A similar pattern is observed during the early stages of fermentation of beer worts and wine musts (22). However, once depletion of the media results in sufficiently low nutrient concentrations to limit cell growth, yeast undergo divergent responses that reflects the nutrients available in the media and the cell's microenvironment. At the diauxic shift, when fermentable carbon sources are exhausted, cells transiently arrest and then reprogram their metabolic patterns to metabolize ethanol and continue slow, vegetative growth (52). Coincident with this switch, cells may become flocculent or change morphology. Later in the fermentation, when confronted by oxygen depletion, critical deprivation of a complex nutrient or complete carbon or nitrogen source starvation, haploid and diploid cells arrest in stationary phase, a $G_{o}$ exit from the cell cycle. During conditions of moderate nitrogen starvation and when non-fermentable carbon sources and oxygen are available, diploid cells can enter meiosis and perform sporulation before arresting. However, during moderate nitrogen limitation in the presence of adequate fermentable carbon source, a situation that wild yeasts may experience when colonizing ripened fruits, yeast continue slow vegetative growth and perform a dimorphic switch (17).

This dimorphic transition is induced by starvation for a nitrogen source and is controlled directly or indirectly by the RAS signal transduction pathway. Pseudohyphal growth requires the polar budding pattern of a/ $\alpha$ diploid cells; haploid axially budding cells of identical genotype cannot undergo this dimorphic transition. Pseudohyphal growth in S. cerevisiae is a unique type of polarized cell division that requires unipolar budding and a change in cellular morphology that results in the formation of macroscopic structures emanating away from the colony into unpopulated substrate (Fig. 1). Gimeno et al. (17) proposed that the role of the diploid budding pattern is to permit otherwise sessile cells to forage for nutrients and substrate at a distance from their initial colonization site.

According to Lorenz and Heitman (35), the high-affinity ammonium permease Mep2 is one receptor that cells use to detect nitrogen compounds. Strains lacking Mep2 can acquire ammonium and grow at normal rates but do not form filaments in response to ammonium limitation. These results suggest that Mep2 senses ammonium starvation and produces a signal leading to filamentous differentiation. Mep1 may also play a role in nitrogen sensing, and perhaps Mep1 and Mep2 signals are integrated to provide a more accurate measure of nitrogen availability.

Amino acid concentrations also affect filamentous growth, either by providing a nitrogen source or via an independent signalling mechanism. Klasson et al. (21) showed that mutations in the $S S Y 1$ amino acid permease or the PTR 3 peptide permease regulator induce elongation. Mutations of $S R H 3$, a gene 


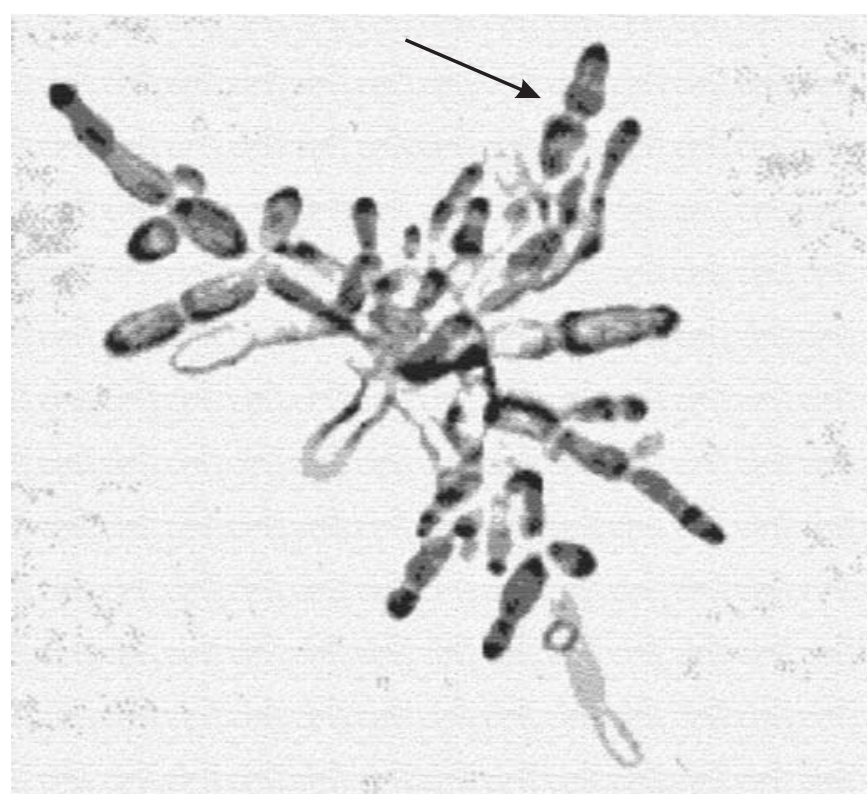

Figure 1. Pseudohyphae of Saccharomyces cerevisiae. Shown are cells containing an activated mitogen-activated protein (MAP) kinase pathway that are growing in low-nitrogen medium. The arrow points to a constriction between the two cells, which is characteristic of pseudohyphae (Reprinted from Madhani and Fink (38)).

required for amino acid uptake, enhance the pseudohyphal phenotype (17). In the nitrogen regulation pathway, the regulator $M K S 1$ acts upstream of the transcription factors URE2 and $G L N 3$ to promote transcription of DAL5, an allantoate and ureidosuccinate permease. Overproduction or depletion of $M k s 1$ reduces filamentation on low nitrogen media (13). Deletion of URE2 and GLN3 also results in the loss of filament formation in response to low nitrogen (35).

The two best characterized pathways regulating filament formation are the cAMP-dependent protein kinase (Protein Kinase A, PKA) and STE MAPK cascades (reviewed by 3, 12, 28, 45, 48; see Figs. 2 and 3). In yeast vegetative growth, activation of Ras 2 stimulates the adenylate cyclase Cyr1 and elevates intracellular cAMP concentrations (Fig. 2). cAMP activates the yeast PKAs, each of which consists of one of three catalytic subunits, Tpk1-3, that form a complex with a single cAMP-binding regulatory subunit, Bcy1 (46). Constitutive activation of RAS2 induces filamentous growth even in the absence of nitrogen starvation (17).

In addition to stimulating PKA activity, Ras 2 also affects filamentous growth via a MAPK signalling cascade (42; Fig. 3 ). The filamentous MAPK cascade contains the protein kinases Ste20 (MAPKKKK), Ste11 (MAPKKK), Ste7 (MAPKK), Kss1 (MAPK) and the transcription factor Ste12 (48).

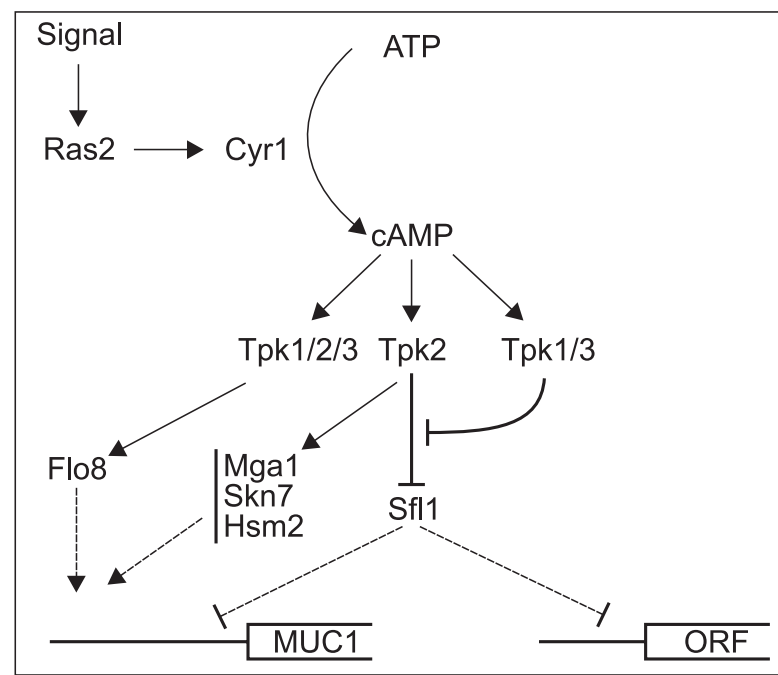

Figure 2. cAMP-PKA pathway regulates filamentous growth in S. cerevisiae. Activation of Ras 2 stimulates adenylate cyclase, Cyr1, and the resulting increase in cAMP level causes an activation of the Tpks. These specifically activate or inhibit a number of proteins which act on different target genes. Arrows indicate activation, lines with bars indicate inhibition, broken lines are used for tentative interactions (Reprinted from Gancedo (14)).

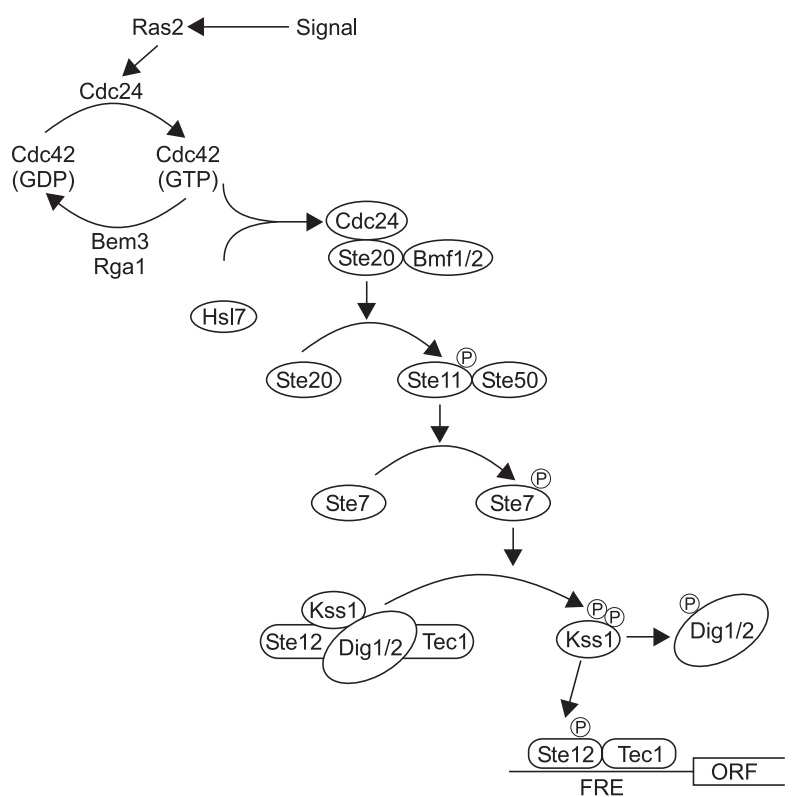

Figure 3. MAPK pathway regulates filamentous growth in $S$. cerevisiae. External signals activate Ras 2 which, in turn, through a series of intermediate steps, causes the phosphorylation of the MAPKKK Ste11, the MAPKK Ste7 and the MAPK Kss1. The final targets are genes with a FRE element in their promoter. Arrows indicate activation. (Reprinted from Gancedo (14)). 
Kss 1 can both activate and inhibit filamentous growth $(2,7)$. The activation-repression system of Kss1 may provide a mechanism for cells to isolate invasive and pseudohyphal growth signals through the MAPK cascade from pheromone and osmotic shock signals through the same pathway (44).

The PAK kinase Ste20 and the MEK kinase Ste11 appear to integrate multiple signals to modulate activation of the filamentous MAPK pathway. When bound to GTP, Cdc42 binds and activates Ste20 and requires Ste20 to induce filamentous growth $(41,47)$. The transcription factor Tec1 is required for filamentous growth stimulated by the MAPK cascade but not by activated PKA (46). Both Ste12 and Tec1 bind to filamentous and invasion response elements (FREs), including a FRE in the TEC1 promoter (37). Other transcription factors are also required for filamentous differentiation, like Flo8 and Phd1, the last one when overexpressed $(6,16,31,32)$.

\section{AGAR INVASIVENESS}

In haploid yeasts, nutrient limitation causes a similar developmental switch that allows cells to penetrate the surface of an agar medium in a process called invasive growth $(1,24,29,38)$.

Cullen and Sprague Jr. (8) obtained evidence that depletion of glucose (or other fermentable sugars) causes haploid invasive growth. They observed by the plate-washing assay that wildtype cells exhibited constitutive invasion on rich medium lacking glucose (Fig. 4). On synthetic medium lacking glucose, cells adopted an elongated morphology, a unipolar budding pattern, and invaded the agar - phenotypes that were completely suppressed by glucose. Strikingly, the elongated cell morphology of most hyper-invasive growth mutants was also supressed by glucose. The glucose control proteins Snf1 and Sip4 had dramatic, albeit opposite effects on invasive growth. In contrast, the absence of fixed nitrogen, amino acids, or nucleotides did not cause invasion. The Ras pathway is required for filamentation and may connect to glucose depletion by sensing the level of cAMP in the cell, which is influenced by glucose concentration (17).

The secretion of hydrolytic enzymes is likely to be an important factor permitting invasive growth. Lytic enzymes capable of hydrolyzing polysaccharides may be secreted by strains capable of pseudohyphal growth. The secretion of proteases is common to many invading pathogens such as Candida albicans (36). The invasive habit of pseudohyphal $S$. cerevisiae cells may be a growth pattern used in nature to penetrate natural substrates such as grapes, according to Gimeno et al. (17).

Guo et al. (18) found a Saccharomyces gene family involved in invasive growth, cell-cell adhesion and mating, the flocculin genes. Although they differ in their specificities, many of these proteins can substitute for each other when overexpressed. For example, Flo11p is required during vegetative growth for haploid

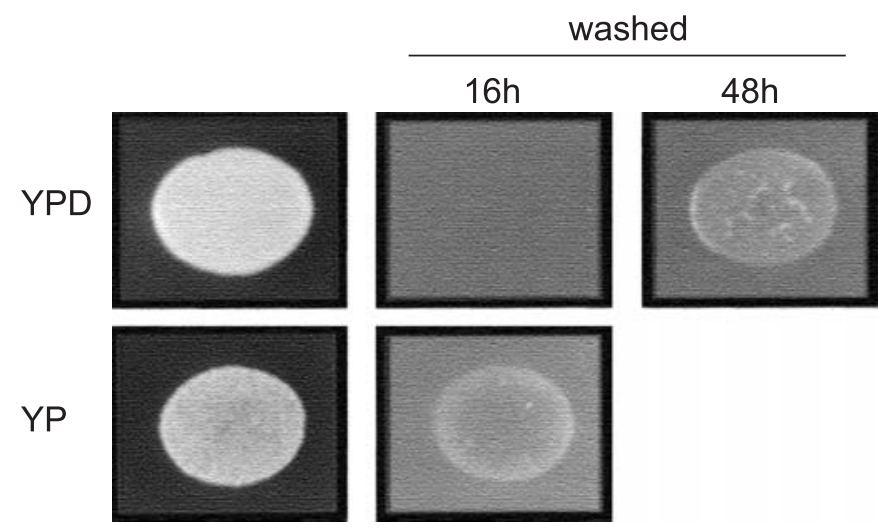

Figure 4. Removal of glucose causes constitutive invasion. Equal concentrations of cells were spotted onto YPD (plus glucose) or YP medium (minus glucose), incubated for $16 \mathrm{~h}$ and $48 \mathrm{~h}$, and photographed. Growth of cells on YP presumably occurred using poor carbon sources present in the yeast extract or agar. (Reprinted from Cullen and Sprague Jr (8)).

invasion and diploid filamentation, whereas Fig2p is required for mating. When overexpressed, Flo11p and Fig2p can function in mating, invasion, filamentation and flocculation.

Pseudohyphal growth of diploid cells and invasiveness of haploids present very similar requirements. Both depend on the MAPK cascade, starting with activation of $\mathrm{Cdc} 42$, including the Ste20, Ste11, Ste7 and Kss1 proteins and their downstream targets, the transcription factors Ste12 and Tec1 $(30,42,43,50)$. Flo8 and Muc1/Flo11 are also required for the morphogenetic change of both haploids and diploids. Finally the PKA pathway plays a role in haploids as it does in diploids. However, the regulation of these pathways is different in the two types of cells.

The yeast Ste 12 transcription factor, which regulates mating and filamentous growth, is bound to distinct program-specific target genes dependent on the developmental condition. This condition-dependent distribution of Ste12 requires concurrent binding of the transcription factor Tec 1 during filamentation and is differentially regulated by the MAP kinases Fus3 and Kss1 (59).

The most striking difference between the two types of cells appeared to be that haploids are able to invade agar in the presence of a good nitrogen source, while diploids are not (50). However, in a diploid growing on a rich medium (YP), filamentation and invasiveness may be induced by cAMP together with a stressful condition such as poor carbon source or the presence of aliphatic alcohols (14).

Zaragoza and Gancedo (58) concluded that pseudohyphal growth is a physiological response to both starvation and a stressful environment. In the first case, it would allow yeasts 
to forage for nutrientes which may be present in the vicinity, in the second case it would facilitate the escape from harmful agents.

Mating pheromones regulate invasive and filamentous growth of haploid $S$. cerevisiae strains. In the wild, most strains of $S$. cerevisiae are diploid, and the haploid state of the life cycle essentially represents gametes that are short-lived in nature. An elaborate pattern of axial budding has evolved in haploid yeast cells and is thought to promote more rapid mating and diploidization following meiosis. Thus, the main activity of haploid yeast strains would appear to be locating a mating partner. Recent studies using genome arrays reveal that pheromone induces several genes that are known to be induced during filamentous growth, including a hydrolytic enzyme encoded by the PGU1 gene $(39,51)$. Remarkably, low concentrations of mating pheromones were found to increase agar-invasive growth (51).

Lo and Dranginis (33) observed that cells of $S$. cerevisiae strain $\sum 1278$ b with deletions of FLO11 do not form pseudohyphae as diploids nor invade agar as haploids. In rich media, FLO11 is regulated by mating type; it is expressed in haploid cells but not in diploids. Upon transfer to nitrogen starvation media, however, FLO11 transcripts accumulate in diploid cells, but not in haploids. Overexpression of Floll in diploid cells, which are otherwise not invasive, enables them to invade agar. Thus, the mating type repression of FLO11 in diploids grown in rich media suffices to explain the inability of these cells to invade.

The fact that mothers and daughters stay attached in the pseudohyphal mode of growth is another important factor contributing to the ability to invade agar. If transcription of CTS1, encoding the chitinase involved in degradation of the primary septum, is abolished, either by gene deletion or transcription factor Ace2 deletion, cells invade agar. Chitinase activities are much lower in strains that grow pseudohyphally than in strains that cannot (20). Therefore, the cell wall is crucial for pseudohyphal growth (58), since the proteins incorporated in the wall and cell wall chitin metabolism are important determinants for the ability to invade agar, one of the most striking features of pseudohyphally growing cells.

\section{ALCOHOL-INDUCED FILAMENTATION}

Microorganisms either secrete or excrete a wide variety of compounds. Some of these substances result from normal metabolic processes, such as alcohols in fermentative yeast. Although ethanol is the primary fermentation product in $S$. cerevisiae, the yeast produces a variety of other alcohols, mostly products of branched-chain amino acid metabolism known collectively as fusel alcohols. The chief constituents of fusel oil are isoamyl alcohol (IAA) and n-amyl alcohol (around 55.3\%), active amyl alcohol, isobutyl alcohol, n-butanol, n-propanol, various esters of these alcohols and lesser quantities of nhexanol (57).

At a concentration of $0.5 \%(\mathrm{v} / \mathrm{v})$, isoamyl alcohol induced the formation of hyphal-like extensions in haploid and diploid strains of $S$. cerevisiae in liquid complex medium. These extensions, which develop via bud initiation and elongation, undergo DNA replication and nuclear division and appear similar in many respects to an aberrant form of the cell division cycle. $\mathrm{N}$-amyl alcohol was equally effective as isoamyl alcohol to induce hyphal-like extension (10). In this paper, the author made a clear distinction between 'hyphal-like extensions' and pseudohyphae, which are defined there as chains of regularshaped, elongated cells in which polar budding predominates. A hyphal-like extension is taken to mean a structure originating from a bud which has undergone abnormal length extension so as to exceed the length of the mother cell from which it arose, but without the isotropic swelling characteristic of the normal yeast cell cycle (Fig. 5).

Dickinson (10) also showed that in nitrogen-poor conditions, leucine induced the formation of hyphal-like extensions. When this amino acid was the sole source of nitrogen, the yeast produced large amounts of isoamyl alcohol, as expected $(11,57)$.

Martinez-Anaya (40) observed that IAA acts by decoupling budding from the nuclear cycle, inducing the rapid formation of linear chains of anucleate buds, each of which is accompanied by the formation of a septin ring at its neck. Subsequently, mitosis resumes so that each bud acquires a nucleus and the buds elongate to produce the characteristic pseudohyphal form (Fig. 6). This process requires the activity of SWE1, SLT2 (MPK1) and PHO85. Sic1 depletion may be responsible for the effect of IAA, because the forced reduction of Sic1 expression, using antisense mRNA, mimics the effect of IAA.

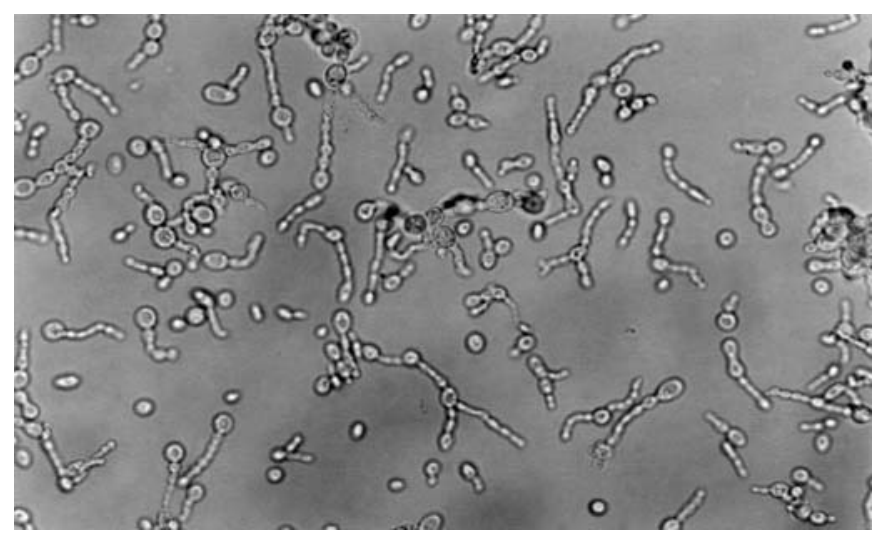

Figure 5. Filamentous form of a $S$. cerevisiae industrial strain. Cells were grown in YEPD agar $+0.8 \%$ IAA, showing aberrant and elongated morphology, distinct from pseudohyphae morphology. (Reprinted from Ceccato-Antonini and Silva (5)). 


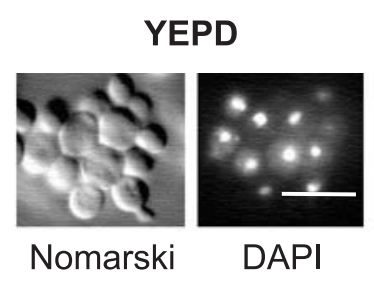

YEPD + $0.5 \%$ IAA

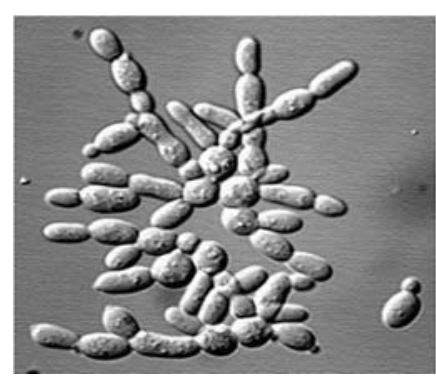

Nomarski

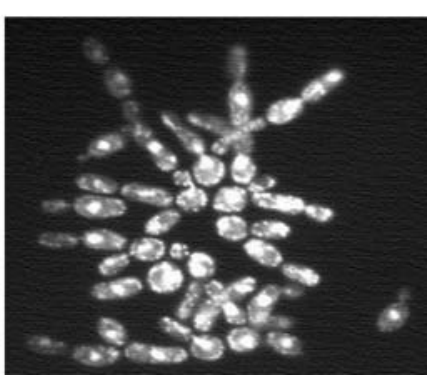

DAPI
Figure 6. S. cerevisiae haploid cells form filaments when incubated overnight in the presence of $0.5 \%$ IAA. Cells grow much bigger than non-stimulated cells (top panel) and adopt morphologies that resemble pseudohyphae. Large cells within the group have a nucleus each (DAPI panel), however small buds and the small compartments between large cells are anucleated (Reprinted from Martinez-Anaya (40)).

$S W E 1$ is essential for pseudohyphal differentiation under a number of nonstandard assay conditions including altered temperature and increased nitrogen. $S W E 1$ is also required for pseudohyphal growth in the absence of TECl and for induction of filamentation by butanol, a related phenomenon. La Valle and Wittenberg (26) concluded that the Swe1 kinase modulates filamentous development under a broad spectrum of conditions and that its role is partially redundant with the Tec1 and Flo8 transcription factors.

Lorenz et al. (34) demonstrated a role for various alcohols in both cellular and colony morphology in $S$. cerevisiae. These alcohols (ethanol, methanol, propanol, isopropanol, butanol, isobutanol, isoamyl and amyl alcohol) stimulated haploid cells to differentiate into a filamentous form similar to diploid-specific, nitrogen-starvation induced, pseudohyphal development. Both of these phenomena involve an elongated cell morphology, alteration in budding pattern, and a dependence on elements of the pheromone-responsive MAPK pathway.

These phenotypes were strongly dependent on the particular yeast strain under study. The filament formation is a strain-specific phenomenon. The structures formed by strains of the $\Sigma 1278 \mathrm{~b}$ background are strikingly similar to pseudohyphal cells, with elongated, cylindrical cells. W303 derivatives, however, adopted a variety of morphologies, including ellipsoidal yeast-form cells, elongated, cylindrical shapes, and rounded yeast cells projecting a thin, hyphal projection reminiscent of germ tube formation in $C$. albicans. In contrast, strains of the S288c lineage seem completely unaffected by the presence of these alcohols. Liu et al. (31) showed that this defect in dimorphism results from a nonsense mutation in the FLO8 gene. This defect in FLO8 blocks pseudohyphal growth in diploids, haploid invasive growth and flocculation. Since several strains of S. cerevisiae are dimorphic and have a funcional FLO8 gene, the authors suggested that the FLO8 mutation was selected during laboratory cultivation. This mutation reduces expression of FLO1, which encodes a large cell surface protein that bridges cells by a divalent cation-requiring binding interaction and thereby makes S288c non-flocculent. This strain is non-adherent as a haploid and non-filamentous as a diploid because of the low expression of both genes.

\section{CONSIDERATIONS AND APPLICATIONS}

It is interesting to observe that, as Kron (23) says in his paper, despite 50 years of genetics that have defined the pathways in nearly every aspect of yeast physiology, it is only in the past 10 years that filamentous growth in S. cerevisiae has been subjected to genetic analysis. Only rare observations of this phenomenon in S. cerevisiae appeared in the literature before 1992. One possible explanation is that the strains of yeast commonly found in laboratories are generally incapable of filamentous growth.

S288c, or a strain derived from it, has generally provided the starting point for constructing the strain background because its cells are easily dispersed. While selecting for easy dispersion, it now appears that the researchers also selected against dimorphism. Kron (23) reviewed the domestication of budding yeast, showing a common origin for the yeast laboratory strains. He also stressed that the laboratory harbors microorganisms are importantly different from their wild cousins, being these distinctions as subtle as a single base pair.

In industrial processes, the manner of organism proliferation, whether in a dispersed or aggregated form, is potentially a limiting factor in production of the desired metabolite(s), utilization of the growth medium and/or separation of cell mass from the soluble product. The classic example of self-clearing of beers at the end of the fermentation by the flocculation and settling of the ale yeast underlines that control over cell morphology and/or cell-cell adhesin is a highly desirable characteristic of an industrial microorganism (19,54).

A detailed understanding of how metabolite sensing and signalling leads to changes in physical properties of cells will be critical for cellular engineering approaches to control dimorphism. For example, maintaining cell dispersion is desired during a fermentation to maximize mass transport and reaction rates but inducing flocculation can facilitate separation of the cells from the fermentation products (44). 
S. cerevisiae IFO 0203, a polyploid yeast used in ethanol production in Japan, grows as ovoid cells in unstirred batch culture and on fully nutritive agar plates. Extensively branched pseudohyphae formed on $0.01 \% \mathrm{w} / \mathrm{v}$ ammonium sulphate plates within a few days. In continuous culture with high oxygen supply and limiting glucose, cells were elongated but growth was vigorous and the daughter cells separated well after budding. Limitation of growth by either nitrogen source or oxygen during continuous culture resulted in formation of truncated, ocasionally branched, pseudohyphae up to five cells in length (25).

Using two industrial strains for ethanol production, CeccatoAntonini and Silva (5) observed transition to hyphal-like extensions or pseudohyphae (clusters of cells) upon addition of IAA from 0.3 to $0.9 \% \mathrm{v} / \mathrm{v}$ in YEPD Agar. All the alterations were reversible when the yeasts were reinoculated in YEPD alone. Although pseudohyphae is a result of nitrogen-limited medium, they observed them as a result of IAA addition. The yeast filamentous morphology can be troublesome to the fermentative process like formation of a 'foam' (yeast cell concentration) at the top of the fermentation tank, gas jailing into the tanks, sugar cane juice flowing out the tanks, with sugar and alcohol loss (4).

It should be kept in mind that adhesion and morphology are not the only characteristics that change during the dimorphic transition. Many fungi also switch their patterns of metabolic conversions, gene expression and protein secretion $(55,56)$. Yeast form and filamentous cells also differ in their expression and accumulation of undesirable cell constituents and the ease with which cells can be disrupted or fractionated (15).

Clearly, active control of dimorphic growth can take advantage of these circuits to increase uptake of reactants or secretion of products in industrial applications or to potentially provide new strategies to combat colonization or invasion by dimorphic fungi.

\section{ACKNOWLEDGMENTS}

The authors wish to thank $\mathrm{CNPq}$ for the post-doctoral grant for the first author (process no. 200678/01-9).

\section{RESUMO}

\section{Filamentação em Saccharomyces cerevisiae}

O dimorfismo em fungos é um fenômeno complexo acionado por um grande número de fatores ambientais e consiste num padrão alternante e reversível de crescimento, oscilando entre formas elípticas e filamentosas de células. É de grande importância o entendimento dos mecanismos que regulam esses eventos devido as suas implicações na patogenicidade, diferenciação celular e indústria. Células diplóides de
Saccharomyces cerevisiae mudam de células brotantes para pseudohifas quando em condições limitantes de nitrogênio, o que confere às células uma vantagem na procura por alimento. A deficiência de nitrogênio é 'percebida' por pelo menos dois caminhos sinalizadores: 'MAP kinase' (MAPK) e 'PKA' (cAMPdependent protein kinase A). O resultado dessa sinalização é a expressão de genes específicos para filamentação, cujos perfis de expressão mudam e são acompanhados por um retardo da fase $\mathrm{G} 2$ do ciclo celular e um período prolongado de crescimento polarizado. Células haplóides mostram um tipo de crescimento similar após prolongada incubação em meio rico. As células formam cadeias e invadem o ágar na borda da colônia, mas não se tornam alongadas. Esse tipo de crescimento é conhecido como crescimento invasivo haplóide. Os álcoois podem também induzir crescimento filamentoso em $S$. cerevisiae, ocasionando uma morfologia alongada e aberrante. Nesse artigo revisamos as três formas de crescimento filamentoso incluindo os caminhos envolvidos na percepção, sinalização e transdução do sinal durante o crescimento filamentoso.

Palavras-chave: filamentação, Saccharomyces cerevisiae, pseudohifas

\section{REFERENCES}

1. Banuett, F. Signalling in the yeasts: an informational cascade with linkes to the filamentous fungi. Microbiol. Mol. Biol. Rev., 62(2):249274, 1998.

2. Bardwell, L.; Cook, J.G.; Zhu-Shimoni, J.X.; Voora, D.; Thorner, J. Differential regulation of transcription: repression by unactivated mitogen-activated protein kinase Kss1 requires the Dig1 nd Dig2 proteins. Proc. Natl. Acad. Sci. USA, 95:15400-15405, 1998.

3. Borges-Walmsley, M.I.; Walmsley, A.R. cAMP signalling in pathogenic fungi: control of dimorphic switching and pathogenicity. Trend. Microbiol., 8:133-141, 2000.

4. Ceccato-Antonini, S.R.; Parazzi, C. Monitoramento microbiológico da fermentação etanólica: uma experiência. Jornal Cana, jan/2000, p. $25-26$.

5. Ceccato-Antonini, S.R.; Silva, P.C. Hyphal-like extension and pseudohyphal formation in industrial strains of yeasts induced by isoamyl alcohol. Braz. J. Microbiol., 33:211-214, 2002.

6. Chandarlapaty, S.; Errede, B. Ash1, a daughter cell-specific protein, is required for pseudohyphal growth of Saccharomyces cerevisiae. Mol. Cell. Biol., 18(5):2884-2891, 1998.

7. Cook, J.G.; Bardwell, L.; Thorner, J. Inhibitory and activating functions for MAPK Kss1 in the $S$. cerevisiae filamentous-growth signalling pathway. Nature, 390:85-88, 1997.

8. Cullen, P.J.; Sprague JR., G.F. Glucose depletion causes haploid invasive growth in yeast. Proc. Natl. Acad. Sci. USA, 97(25):13619-13624, 2000 .

9. Dickinson, J.R. Irreversible formation of pseudohyphae by haploid Saccharomyces cerevisiae. FEMS Microbiol. Lett., 119:99-104, 1994.

10. Dickinson, J.R. 'Fusel' alcohols induce hyphal-like extensions and pseudohyphal formation in yeasts. Microbiology, 142:1391-1397, 1996.

11. Dickinson, J.R.; Lanterman, M.M.; Danner, D.J.; Pearson, B.M.; Sanz, P.; Harrison, S.J.; Hewlins, M.J.E. A ${ }^{13} \mathrm{C}$ nuclear magnetic resonance investigation of the metabolism of leucine to isoamyl 
alcohol in Saccharomyces cerevisiae. J. Biol. Chem., 272:2687126878, 1997.

12. D'Souza, C.A.; Heitman, J. Conserved cAMP signalling cascades regulate fungal development and virulence. FEMS Microbiol. Rev., 25:349-363, 2001

13. Edskes, H.K.; Hanover, J.A.; Wickner, R.B. Mks1p is a regulator of nitrogen catabolism upstream of Ure2p in Saccharomyces cerevisiae. Genetics, 153:585-594, 1999.

14. Gancedo, J.M. Control of pseudohyphae formation in Saccharomyces cerevisiae. FEMS Microbiol. Rev., 25:107-123, 2001.

15. Gibbs, P.A.; Seviour, R.J.; Schmid, F. Growth of filamentous fungi in submerged culture: problems and possible solutions. Crit. Rev. Biotechnol., 20:17-48, 2000.

16. Gimeno, C.J.; Fink, G.R. Induction of pseudohyphal growth by overexpression of PHD1, a Saccharomyces cerevisiae gene related to transcriptional regulators of fungal development. Mol. Cell. Biol., 14(3):2100-2112, 1994.

17. Gimeno, C.J.; Ljungdahl, P.O.; Styles, C.A.; Fink, G.R. Unipolar cell divisions in the yeast Saccharomyces cerevisiae lead to filamentous growth: regulation by starvation and RAS. Cell, 68:10771090, 1992.

18. Guo, B.; Styles, C.A.; Feng. Q.; Fink, G. A. Saccharomyces gene family involved in invasive growth, cell-cell adhesion, and mating. Proc. Natl. Acad. Sci. USA, 97(22):12158-12163, 2000.

19. Hammond, J.R. Genetically-modified brewing yeasts for the $21 \mathrm{st}$ century. Progress to date. Yeast, 11:1613-1627, 1995.

20. King, L.; Buttler, G. Ace2p, a regulator of CTS1 (chitinase) expression, affects pseudohyphal production in Saccharomyces cerevisiae. Curr. Genet., 34:183-191, 1998.

21. Klasson, H.; Fink, G.R.; Ljungdahl, P.O. Ssy1p and Ptr3p are plasma membrane components of a yeast system that senses extracellular amino acids. Mol. Cell Biol., 19:5405-5416, 1999.

22. Kleyn, J.; Hough, J. The microbiology of brewing. Annu. Rev. Microbiol., 25:583-608, 1971.

23. Kron, S.J. Filamentous growth in budding yeasts. Trends Microbiol., 5:450-454, 1997

24. Kron, S.J.; Gow, N.A. Budding yeast morphogenesis: signalling, cytoskeleton and cell cycle. Curr. Opin. Cell Biol., 7:845-855, 1995.

25. Kuriyama, H.; Slaughter, J.C. Control of cell morphology of the yeast Saccharomyces cerevisiae by nutrient limitation in continuous culture. Lett. Appl. Microbiol., 20:37-40, 1995.

26. La Valle, R.; Wittenberg, C. A role for the Swe1 checkpoint kinase during filamentous growth of Saccharomyces cerevisiae. Genetics, 158:549-562, 2001.

27. Lee, B.N.; Elion, E.A.; The MAPKKK Ste11 regulates vegetative growth through a kinase cascade of shared signalling components. Proc. Natl. Acad. Sci. USA, 96:12679-12684, 1999.

28. Lengeler, K.B.; Davidson, R.C.; D’Souza, C.; Harashima, T.; Shen, W.C.; Wang, P.; Pan, X.; Waugh, M.; Heitman, J. Signal transduction cascades regulating fungal development and virulence. Microbiol. Mol. Biol. Rev., 64:746-785, 2000.

29. Levin, D.E.; Errede, B. The proliferation of MAPkinase signalling pathways in yeast. Curr. Opin. Cell Biol., 7:197-202, 1995.

30. Liu, H.; Styles, C.A.; Fink, G.R. Elements of the yeast pheromone response pathway required for filamentous growth of diploids. Science, 262:1741-1744, 1993.

31. Liu, H.; Styles, C.A.; Fink, G.R. Saccharomyces cerevisiae S288c has a mutation in FLO8, a gene required for filamentous growth. Genetics, 144:967-978, 1996.

32. Lo, H.J.; Kohler, J.R.; DiDomenico, B.; Loebenberg, D.; Cacciapuoti, A.; Fink, G.R. Nonfilamentous C. albicans mutants are avirulent. Cell, 90:939-949, 1997.

33. Lo, W.S.; Dranginis, A.M. The cell surface floculin Flo11 is required for pseudohyphae formation and invasion by Saccharomyces cerevisiae. Mol. Biol. Cell, 9:161-171, 1998.
34. Lorenz, M.C.; Cutler, N.S.; Heitman, J. Characterization of alcoholinduced filamentous growth in Saccharomyces cerevisiae. Mol. Biol. Cell, 11:183-199, 2000.

35. Lorenz, M.C.; Heitman, J. The MEP2 ammonium permease regulates pseudohyphal differentiation in Saccharomyces cerevisiae. EMBO J., 17:1236-1247, 1998.

36. Macdonald, F.; Odds, F.C. Virulence for mice of a proteinase-secreting strain of Candida albicans and a proteinase deficient mutant. $J$. Gen. Microbiol., 129:431-438, 1983.

37. Madhani, H.D.; Styles, C.A.; Fink, G.R. MAP kinases with distinct inhibitory functions impart signalling specificity during yeast differentiation. Cell, 91:673-684, 1997.

38. Madhani, H.D.; Fink, G.R. The control of filamentous differentiation and virulence in fungi. Trends Cell Biol., 8:348-353, 1998.

39. Madhani, H.D.; Galitski, T.; Lander, E.S.; Fink, G.R. Effectors of a developmental mitogen-activated protein kinase cascade revealed by expression signatures of signaling mutants. Proc. Natl. Acad. Sci. USA, 96:12530-12535, 1999.

40. Martinez-Anaya, C. Isoamyl alcohol induces filamentous growth by decoupling budding from nuclear cycle in Saccharomyces cerevisiae. Sheffield, 2002, 137p. (PhD thesis. University of Sheffield).

41. Mosch, H.U.; Kohler, T.; Braus, G.H. Different domains of the essential GTPase Cdc 42p required for growth and development of Saccharomyces cerevisiae. Mol. Cell Biol., 21:235-248, 2001.

42. Mosch, H.U.; Kubler, E.; Krappmann, S.; Fink, G.R.; Braus, G.H. Crosstalk between the Ras2p-controlled mitogen-activated protein kinase and cAMP pathways during invasive growth of Saccharomyces cerevisiae. Mol. Biol. Cell, 10:1325-1335, 1999.

43. Mosch, H.U.; Roberts, R.L.; Fink, G.R. Ras2 signals via the Cdc42/ Ste20/mitogen-activated protein kinase module to induce filamentous growth in Saccharomyces cerevisiae. Proc. Natl. Acad. Sci. USA, 93:5352-5356, 1996.

44. Palecek, S.P.; Parih, A.S.; Kron, S.J. Sensing, signalling and integrating physical processes during Saccharomyces cerevisiae invasive and filamentous growth. Microbiology, 148:893-907, 2002.

45. Pan, X.; Harashima, T.; Heitman, J. Signal transduction cascades regulating pseudohyphal differentiation of Saccharomyces cerevisiae. Curr. Opin. Microbiol., 3:567-572, 2000.

46. Pan, X.; Heitman, J. Cyclic AMP-dependent protein kinase regulates pseudohyphal differentiation in Saccharomyces cerevisiae. Mol. Cell Biol., 19:4874-4887, 1999.

47. Peter, M.; Neiman, A.M.; Park, H.O.; van Lohuizen, M.; Herskowitz, I. Functional analysis of the interaction between the small GTP binding protein Cdc 42 and the Ste20 protein kinase in yeast. EMBO J., 15:7046-7059, 1996.

48. Posas, F.; Takekawa, M.; Saito, H. Signal transduction by MAP kinase cascades in budding yeast. Curr. Opin. Microbiol., 1:175-182, 1998.

49. Pretorius, I.S. Tailoring wine yeasts for the new millenium: novel approaches to the ancient art of winemaking. Yeast, 16:675-729, 2000.

50. Roberts, R.L.; Fink, G.R. Elements of a single MAP kinase cascade in Saccharomyces cerevisiae mediate two developmental programs in the same cell type: mating and invasive growth. Genes Dev., 8:2974-2985, 1994.

51. Roberts, C.J.; Nelson, B.; Marton, M.J.; Stoughton, R.; Meyer, M.R.; Bennett, H.A.; He, Y.D.; Dai, H.; Walker, W.L.; Hughes, T.R.; Tyers, M.; Boone, C.; Friend, S.H. Signalling and circuitry of multiple MAPK pathways revealed by a matrix of global gene expression profiles. Science, 287:873-880, 2000.

52. Russel, M.; Bradshaw-Rouse, J.; Markwardt, D.; Heideman, W. Changes in gene expression in the Ras/adenylate cyclase system of Saccharomyces cerevisiae: correlation with cAMP levels and growth arrest. Mol. Biol. Cell, 4:757-765, 1993.

53. Sanchez-Martinez, C.; Perez-Martin, J. Dimorphism in fungal pathogens: Candida albicans and Ustilago maydis - similar inputs, different outputs. Curr. Opin. Microbiol., 4:214-221, 2001. 
54. Straver, M.H.; van der Aar, P.C.; Smit, G.; Kijne, J.W. Determinants of flocculence of brewer's yeast during fermentation in wort. Yeast, 9:527-532, 1993.

55. Viard, B.; Kuriyama, H. Phase-specific protein expression in the dimorphic yeast Saccharomyces cerevisiae. Biochem. Biophys. Res. Commun., 233:480-486, 1997.1.

56. Wartmann, T.; Kunze, G. Genetic transformation and biotechnological application of the yeast Arxula adeninivorans. Appl. Microbiol. Biotechnol., 54:619-624, 2000.
57. Webb, A.D.; Ingraham, J.L. Fusel oil. Adv. Appl. Microbiol., 5:317 353, 1963.

58. Zaragoza, O.; Gancedo, J.M. Pseudohyphal growth is induced in Saccharomyces cerevisiae by a combination of stress and cAMP signalling. Antonie van Leeuwenhoek, 78:187-194, 2000.

59. Zeitlinger, J.; Simon, I.; Harbison, C.T.; Hannet, N.M.; Volkert, T.L.; Fink, G.R.; Young, R.A. Program-specific distribution of a transcription factor dependent on partner transcription factor and MAPK signalling. Cell, 113:395-404, 2003. 